\title{
Katherine Dunham's Global Method and the Embodied Politics of Dance's Everyday
}

\author{
Harmony Bench and Kate Elswit \\ Department of Dance, The Ohio State University and The Royal Central School of Speech and Drama, \\ University of London \\ Email: bench.9@osu.edu \\ Email: Kate.Elswit@cssd.ac.uk
}

In a 1950 letter, choreographer Katherine Dunham mentions trouble keeping dancers with her troupe "[i]n spite of the fact that we are the only non-subsidized professional group that has remained self-supporting over these years, and in spite of the fact that we are loved and respected all over the world and work more weeks out of the year than any other dance group in existence."1 Although some of these claims would be challenging to validate empirically, Dunham is not exaggerating when she describes the amount of work it took for her and her dancers to keep going without the benefit of public funding or an enduring private patron. This essay is part of a larger critical mixed methods project on historical dance touring and transmission: Dunham's Data: Katherine Dunham and Digital Methods for Dance Historical Inquiry. We turn here to the scale of the "everyday," beginning by building a daily itinerary of Dunham's travels so as to understand better the global method necessary for her company's survival, and how the ongoing pursuit of solvency propelled her, her performers, and her work into the world.

A precise catalog of travel is particularly important for a choreographer whose artistic practice is uniquely informed by real and imagined engagements with geographic locations-what has been understood as Dunham's diasporic imagination. ${ }^{2}$ Over her eighty-year career, Dunham worked across six continents in many contexts of dance choreography, performance, and pedagogy, from her early anthropological research to curatorial and administrative projects later in life. ${ }^{3}$ Although scholars have tracked Dunham's extensive travels on an ad hoc basis, our work represents the first attempt to build a comprehensive dataset of her whereabouts. We initially began to build this itinerary to understand the relationship between

The writing and datasets are equally coauthored by Kate Elswit and Harmony Bench; the name order is alphabetical. Dunham's Data is supported by a three-year research project grant from the UK Arts and Humanities Research Council (AHRC, AH/R012989/1). Additional support leading to this essay was provided by a Battelle Engineering, Technology, and Human Affairs (BETHA) Endowment Grant from The Ohio State University. With special thanks to Matthew Gorzalski at Morris Library, SIU; and Dunham's Data postdoctoral research assistants Antonio Jiménez Mavillard and Takiyah Nur Amin, as well as the Dunham's Data Advisory Board.

(c) American Society for Theatre Research 2020. This is an Open Access article, distributed under the terms of the Creative Commons Attribution-NonCommercial-NoDerivatives licence (http://creativecommons.org/licenses/by-nc-nd/4.0/), which permits non-commercial re-use, distribution, and reproduction in any medium, provided the original work is unaltered and is properly cited. The written permission of Cambridge University Press must be obtained for commercial re-use or in order to create a derivative work. 
Dunham's choreographic and ethnographic work by analyzing the ways her dances both drew on place and circulated these images, movements, and sounds to other places. In the process of tracking the years of her most significant international touring, we realized how much information was already contained in this reference dataset. We develop the everyday as an intersectional feminist analytic in tandem with our dataset of Dunham's travel to understand better what it took for Dunham to make do by crafting a transnational life-what we call her "global method."

Bodies, bodily experience, and embodiment pose unique challenges for the digital humanities, where recent scholarship has called for greater inclusion of the body and embodiment as part of a critical orientation to data. We have previously used the phrase "movement on the move" to understand not just how dance circulates but also what happens to dancers' bodies as they do so. ${ }^{4}$ Framing bodies within a data context requires acknowledging the risks of dematerialization and critically examining how subjects, agency, and material circumstances are represented within such work. ${ }^{5}$ The conversations about bodies that come out of digital humanities and critical data studies connect to broader discussions regarding the personal nature of data, and how not to lose sight of humanity behind the data. ${ }^{6}$ As scholars of race and technology have elaborated, techniques of quantification such as those we engage here have a long history of dehumanizing Black subjects, from registers of slave ships to police profiling to algorithmic bias. ${ }^{7}$ This is especially important to recognize when seeking to represent Black embodiment and experiences while resisting what Jessica Marie Johnson calls the "devastating thingification of black women, children, and men" that is entangled with the rise of the "independent and objective statistical fact." 8 Examining historical research done in relation to the databases used to track enslaved peoples, Johnson argues for the necessity of "a methodology and praxis that centers the descendants of the enslaved, grapples with the uncomfortable, messy, and unquantifiable, and in doing so, refuses disposability."

Such important work interrogates the transformation of lived experience into data and calls for a humanistic approach that continues to emphasize ambiguity and nontotalizing capture and representation. ${ }^{10}$ It is important to us that every data point in Dunham's Data is curated by hand, and almost entirely from materials that Dunham herself chose to save. Each data point has a story and sometimes multiple, conflicting stories, and we evaluate how best to document Dunham's whereabouts while recognizing that discrepancies are part of the story as well. This intentional data curation draws us closely into Dunham's lived experiences, and we foreground throughout this essay how such curation and visualization operate as modes of inquiry that deepen our understanding of her life. We see Dunham's Data as a whole employing the scholarly methods of dance studies to attend to the bodies in the data, and engaging digital methods to evidence and elaborate bodily experience. We engage with the physicality of embodied knowledge and examine how physicality, in turn, enables bodies to operate as portals for the development and transmission of culture. ${ }^{11}$ This essay is one step in that direction.

In the next section of this paper, we articulate what the scale of the everyday offers as an analytic for dance touring, and propose Dunham as an exemplary case study to construct such an itinerary. We then seek to understand the global method that connects Dunham's mobility to her solvency in terms of patterns of 
transnational travel, which we describe as stays and returns, that far surpassed her contemporaries. We further propose that attention to Dunham's whereabouts day by day can rebalance the geography of Dunham scholarship, including revealing the centrality of nightclub and other nonconcert performances to sustaining the company over time. While Dunham's mobility might appear seamless, both facilitated by and confirming her celebrity status, we turn to a paradigm of friction and flexibility in order to elaborate how Dunham's touring pathways were shaped by a variety of intersecting factors, from the ways racial bias manifested in refusals of lodging, to the capacity to change plans quickly, including by scaling down the size of the company. Dunham's bodily well-being rarely stopped her relentless onward momentum, yet it nonetheless haunts the everyday itinerary we built to document her transnational movement. At the end of this essay, we investigate the cumulative wear and tear that Dunham describes as central to her experiences of keeping going. In so doing, we foreground the embodied labor in Dunham's everyday practices of making do as an African American woman in the midtwentieth century.

\section{Dance Touring at the Scale of the Everyday}

As an analytic, the everyday is a catalyst for shifting scale. ${ }^{12}$ In Mapping Yorùbá Networks, Kamari Maxine Clarke grounds her ethnographic research in a desire to "establish the geographic and temporal scales in which the globalization of ... African-heritage practices play out." ${ }^{13}$ Whereas Clarke is writing about the construction of transnational communities through networks of Yorùbá practitioners, Dunham's Data seeks to understand the ways a single African American dance artist and those in her employ traversed transnational space. However, Clarke's work provides a touchpoint for the importance of understanding transnational circulation at multiple scales. While it is one thing to deal with the idea of dance touring in the abstract, it is another to look at years of movement in terms of the daily experiences, people, and practices that constitute ongoing travel and performance. In this sense, the granularity demanded by the work of manually building datasets serves as a prompt to consider Dunham from the scale of the everyday and, with this collection of so many everydays, to develop a wide-angle survey that contributes to understanding our project's overarching question of how movement moves.

As a critical category, the "everyday" has multiple valences. There is the idea of the "everyday" as a kind of singular yet mundane experience that tends to be repeated from day to day. Looking closely at such particularities of experience additionally turns from the vernacular to the related understanding of "everyday" as dailiness and the sequence that occurs in the lived experience of day after day. ${ }^{14}$ Of particular importance in imagining Dunham's everyday is Katherine McKittrick's intersectional analysis in Demonic Grounds that theorizes the stakes of making visible how Black women's "geographies of the everyday" are lived. ${ }^{15}$ Citing the whiteness inherent in earlier critical texts that presume space as a transparent container for action, as well as the racial violence and dispossession that has historically resulted in blackness being understood as ungeographic (or located spatially only in negative accounts, such as those documenting discrimination), McKittrick argues for "the oppositional implications of saying, thinking, living, 
and writing black geographies."16 An exceptional example of this is Babylon Girls, in which Jayna Brown posits the need to examine the mobility of "journeying black women" artists not as passive commodities or as active exceptions but rather "as critical modern subjects, citizens of the world." ${ }^{17}$ McKittrick and Brown provide frameworks for understanding Dunham's global mobility; following these examples, we rely on Dunham's extraordinary self-archiving to trace the geographies that she constructed through her travels.

In compiling the itinerary that underpins this essay, which represents where Dunham was every single day between 1 January 1950 and 31 December $1953,{ }^{18}$ we consulted performance contracts, receipt books, personal logs and activity diaries, programs, newspaper clippings, and personal and professional correspondence from the Dunham archives at Southern Illinois University, the Missouri Historical Society, the Library of Congress, and elsewhere. To these we added supplemental data sources, including immigration records, local newspapers, and historical transit maps and schedules. ${ }^{19}$ Working at the scale of the everyday, however, we came to recognize that individual items among the voluminous contents of Dunham's archives were not, by themselves, reliable indicators of her whereabouts over time. We developed a more rigorous process for cross-referencing multiple documents than we have for other research subjects, not assuming that Dunham was able to adhere to the tour schedules she included in her correspondence, that contracts or newspaper advertisements accurately reflect the length of a performance run, or that programs contain up-to-date information about company membership. ${ }^{20}$

In the 1950-3 dataset, we locate with a reasonable level of confidence the cities and countries where Dunham was for 98 percent of her days in this four-year period-1,426 out of 1,461 days. We also track, albeit less comprehensively, the accommodations in which she stayed each night; the theatres, nightclubs, television studios, and other locations in which she and the company performed; the mode of transportation used when travel occurred; additional transit cities through which she passed; and whether or not Dunham was likely to be in rehearsals or giving public performances. This process of day-by-day accounting also lends itself to the breakdown of intraday time. For example, Dunham and her company often performed multiple shows in one or more theatres in a given night. Likewise, not only did Dunham engage in business activities during the day, but she also took meetings during intermissions. ${ }^{21}$

While the granularity of the everyday builds on many analog methodological precursors for tracking historical itineraries, ${ }^{22}$ working in a computational framework both prompts precision at a different scale, and offers a means to manipulate large quantities of information for the purposes of analysis. ${ }^{23}$ Tracing Dunham's everyday generates an account of dance history counter to dominant historical approaches that take a midfield view to build broad narratives through a small set of exemplary moments, anecdotally illustrating an argument about the arc of an artist's lifetime or their body of work. Dunham's career as an artist, activist, and teacher is punctuated by many such exceptional moments, which are well represented in the scholarship. In the following sections, we show how the process of accumulating quotidian minutiae produces a rescaling that enables us to step back and observe connections between Dunham's extensive reach as a touring artist and 
her financial precarity. Gathering together Dunham's whereabouts day to day, we see patterns of travel emerge-where Dunham stays for long periods, and also the locations to which she and her company return-and the politics that they in turn index, from support or lack thereof, to inequalities and conditions of transnational mobility, and the physical and emotional tolls that the pursuit of artistic survival through international touring places on the performers' bodies. Many of the material circumstances that come to the fore through this everyday perspective on touring are so familiar to performers that they remain invisible in scholarly analysis. Attending to the everyday thus also amplifies what is implicit in such accounts, giving evidentiary weight to dancers' shared tacit knowledges.

\section{Tracing Dunham's Global Method}

The transnational was more than something that motivated Dunham's movement research or an idea that she represented choreographically onstage. Dunham's international travel began with her anthropological work in the Caribbean in 1935-6, which served as an inspiration for her later choreography. In 1947 she began to perform outside of the United States more regularly with a tour of Mexico, followed by a European tour one year later. The years 1950-3 represented a marked expansion of Dunham's geographical coverage to include countries throughout South America and a brief visit to North Africa. Dunham later added Oceania and East Asia in 1956-7, at the end of which she sustained a severe injury. After a long convalescence and time away from the stage, Dunham resumed her international touring in 1959 before disbanding the company once again during a 1960 European tour. In this section we look to the patterns of Dunham's touring as dynamic spatial histories that reveal her global method.

Transnational mobility is often an abstract concept, but in Figure 1 we use a space-time geography approach to show Dunham's international travel broken down into each of the 1,426 days for which we have location data in the 1950-3 everyday dataset. ${ }^{24}$ This visualization represents time as elevation, beginning in 1950 at the base map, and ending with 1953 at the top. From this map, we can see both the geographical reach of Dunham's travels over these four years, encompassing locations in Europe, North and South America, Africa, and the Caribbean, as well as how cities are connected sequentially by Dunham's movement through them, including repeated returns to specific locations. With just these four years plotted, it becomes possible to imagine what this map will look like once expanded to encompass the decades of Dunham's most substantial international travel. ${ }^{25}$

The geographic expanse of Dunham's touring and the pace of her travel schedule evidence a kind of global audience supporting her work, but it would be a mistake to take this at face value. Rather, keeping moving geographically-in Dunham's proud and frustrated words from the opening paragraph, working "all over the world" and "more weeks out of the year than any other dance group" - was critical in order for her to continue financially. Unlike many dance companies traveling during the early Cold War period, which were subsidized by employment in efforts of cultural diplomacy, ${ }^{26}$ Dunham never received any substantial public funding. Nor did she have a core private patron to shore up her financial security, despite her friendship with philanthropist Doris Duke. 


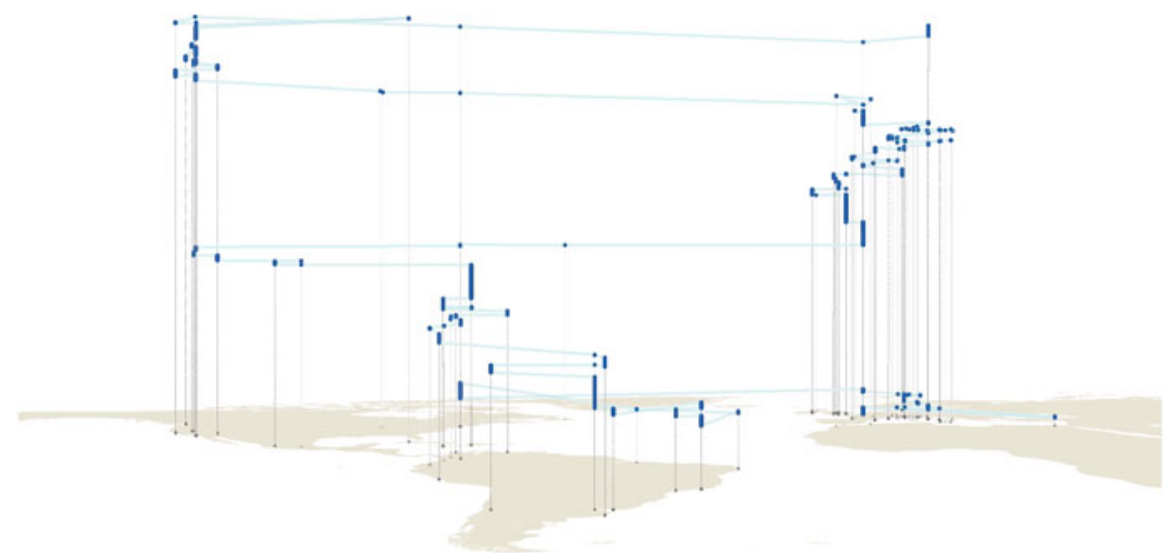

Figure 1. Spatialized sequence of Dunham's 1950-3 destinations. Available as a three-dimensional video flythrough at https://vimeo.com/312137293. The timeline is sequential from the base map upward, beginning with 1950 closest to the map and ending with the last day of 1953 at the top of the image. Vertical extrusions of dots represent lengths of stay in a given location, while vertical lines connect each stay to a city on the map below.

Data: Harmony Bench and Kate Elswit. Visualization: Center for Urban and Regional Analysis (OSU, 2018).

As we combed through archival materials to build this multiyear itinerary, it became apparent how precarious Dunham's solvency was, and how that directly manifested in fluctuating touring pathways. Dunham had to break even or move on. When the company was profitable in a city, their contract was sometimes extended; when they did not do well with a local audience, the contract would be cut short in favor of a new act. Long-planned tours were abandoned at the last minute to be replaced by a string of short engagements nearby. Interconnected with financial viability in this way, the specificity of touring pathways and the length of Dunham's stays thus serve to index audience interest and other factors of support. Scholars in multiple disciplines tend to think of Dunham as a success story of a great artist-which she is-but looking more closely at Dunham's international itinerary complicates that narrative. We therefore also ask: How did Dunham keep going in the face of structural racism and financial precarity? And how might her efforts to keep the company afloat be represented in the ways that scholars account for her international circulation and resulting global legacy?

A daily itinerary rebalances the geography of Dunham scholarship, which tends to focus on five key cities: Paris, Port-au-Prince, Chicago, New York City, and, later, East St. Louis. When we organize Dunham's travels as a timeline sorted by the cities where she spent the most time across repeated trips, however, another story emerges. Figure 2 shows that certain cities such as Paris and Port-au-Prince remain significant when tracking Dunham's whereabouts day by day during this four-year period, while other cities recede. For example, New York plays a significant role in Dunham scholarship thanks to some successful Broadway runs and other performances during the 1940s, as well as her school there from 1944 to 1954. Dunham's early touring centered on the East Coast plus some Midwestern cities, 


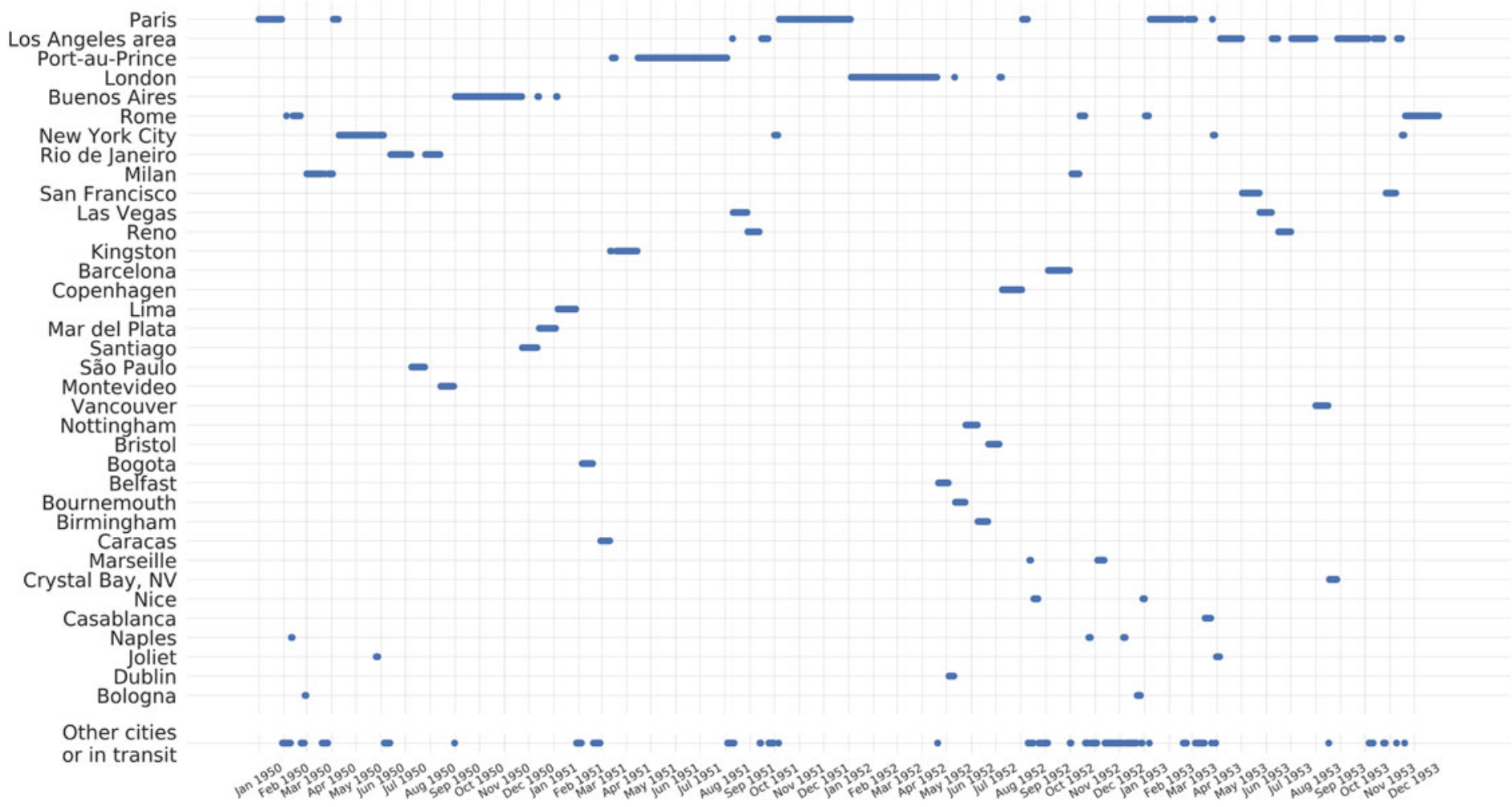

Figure 2. Timeline for cities in which Dunham stayed over seven nights in total, 1950-3. This plots stays and returns in thirty-six key locations, while grouping the remaining forty-seven cities into a single "other cities" category below. Data: Harmony Bench and Kate Elswit. Visualization: Antonio Jiménez Mavillard. An online interactive version of the full timeline and the underpinning data is available to explore at https://dunhamsdata.org/1950-53timeline/ 
which was fairly common by comparison to other well-known US dance companies at this time. ${ }^{27}$ However, from the late 1940s onward, New York and the East Coast circuit became less significant to Dunham's overall trajectory. This had to do both with a higher proportion of international touring on the whole, but also with a critical presence in the West when Dunham was in the United States, on which we elaborate shortly. A daily itinerary thus allows us to trace the many other cities that comprise Dunham's transnational circulation. This includes both the cities where Dunham stayed for long stretches of time, but which have gone unexamined, and the prevalence of smaller cities and towns that were crucial to the company's economic survival.

Accounting for each day, we can better understand Dunham's meaningful patterns of travel over the four years, and assess what these indicate about support and its implications for bodies on the move. When we talk about stays, we are calculating how long Dunham lingered in a place on a given trip for one night or longer, often a sign of audience interest and financial success. Stays are not only made up of performance runs; they also include rehearsing for upcoming shows, as well as time off. During 1950-3, Dunham has 134 stays across at least 83 cities. In addition to the duration of each individual stay, we count cumulative stay durations across multiple trips to the same location, either because she expected repeat successes or because of investments of an affective rather than financial variety. Trips back to the same city across multiple stays are described as returns. ${ }^{28}$

Taking this four-year period as a whole, Dunham's median stay length is three nights. As Figure 3 shows, although a few stays last more than a hundred sequential nights (London and Port-au-Prince), the normal distribution for individual stays is between two nights and just under two weeks. ${ }^{29}$ Clearly the proportions shift over time. In March 1950, Dunham told her mother how exhausting she found two- and three-night engagements; ${ }^{30}$ however, our timelines highlight how her pace subsequently accelerated. For example, in the second half of 1952, a financial downturn in Europe caused Dunham to expand her reach across the continent further in search of audiences. A cluster of "other cities" from August 1952 to March 1953 in Figure 2 stands out as a substantial period during which Dunham moved through cities with cumulative stay values of fewer than seven nights, meaning that when she stayed, it was for only a brief time. Whereas for the South America tour in 1950-1, Dunham's contract with impresario Sol Hurok had specified that they would not be booked in a theatre for less than half a week without Dunham's express permission, ${ }^{31}$ the later period shows an even more rapid movement through new cities. In other words, we are talking about almost constant travel—for Dunham and her performers. During a brief visit home in 1951 by dancer Vanoye Aikens, an Atlanta newspaper feature noted that "periods of rest have been few and far between" ever since he joined Dunham's company nine years earlier. The article specifies that this is Aikens's "first trip home in five years" and that he will remain only a week or so before rejoining the troupe. ${ }^{32}$ As we have continued to expand the daily itinerary beyond this initial 1950-3 dataset, we discover that these patterns of work and travel are not anomalous, but persist across many decades of Dunham's career.

We can further contextualize this pattern of short stays with reference to relative city size. In Figure 4, we have plotted the cumulative number of days that Dunham 


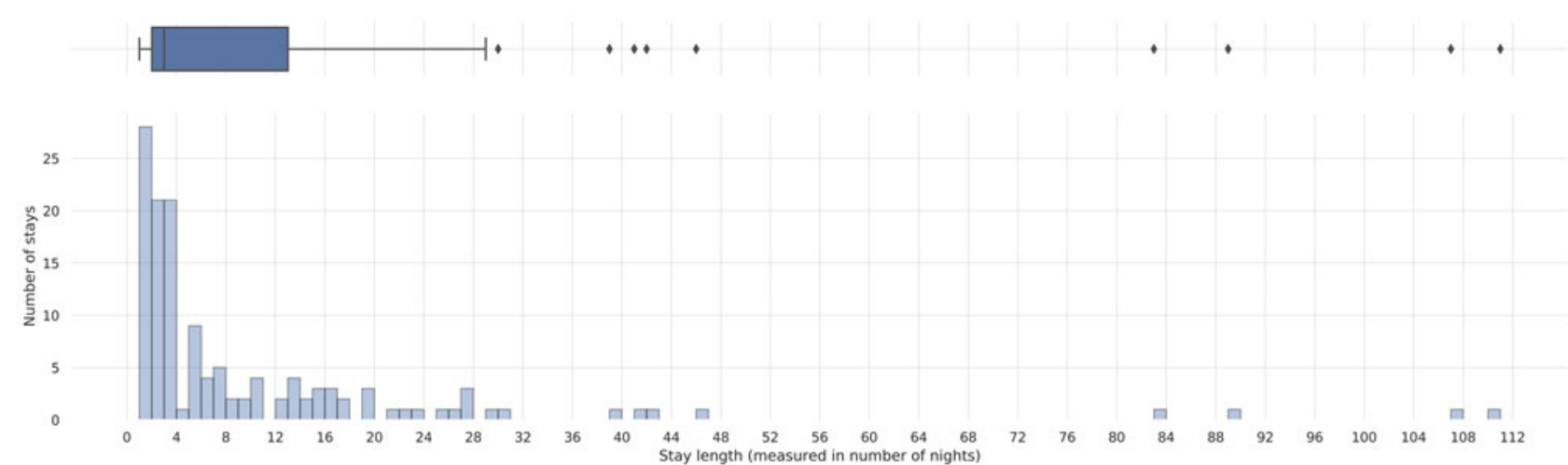

Figure 3. Frequency of nights stayed, 1950-3. This box plot visualizes the distribution of Dunham's stay lengths. The typical distribution is $2-13$ nights, with a maximum typical value of 29.5. Longer stays are outliers. The median distribution is a stay of 3 nights, with 21 percent of her stays lasting a single night.

Data: Harmony Bench and Kate Elswit. Visualization: Antonio Jiménez Mavillard. 


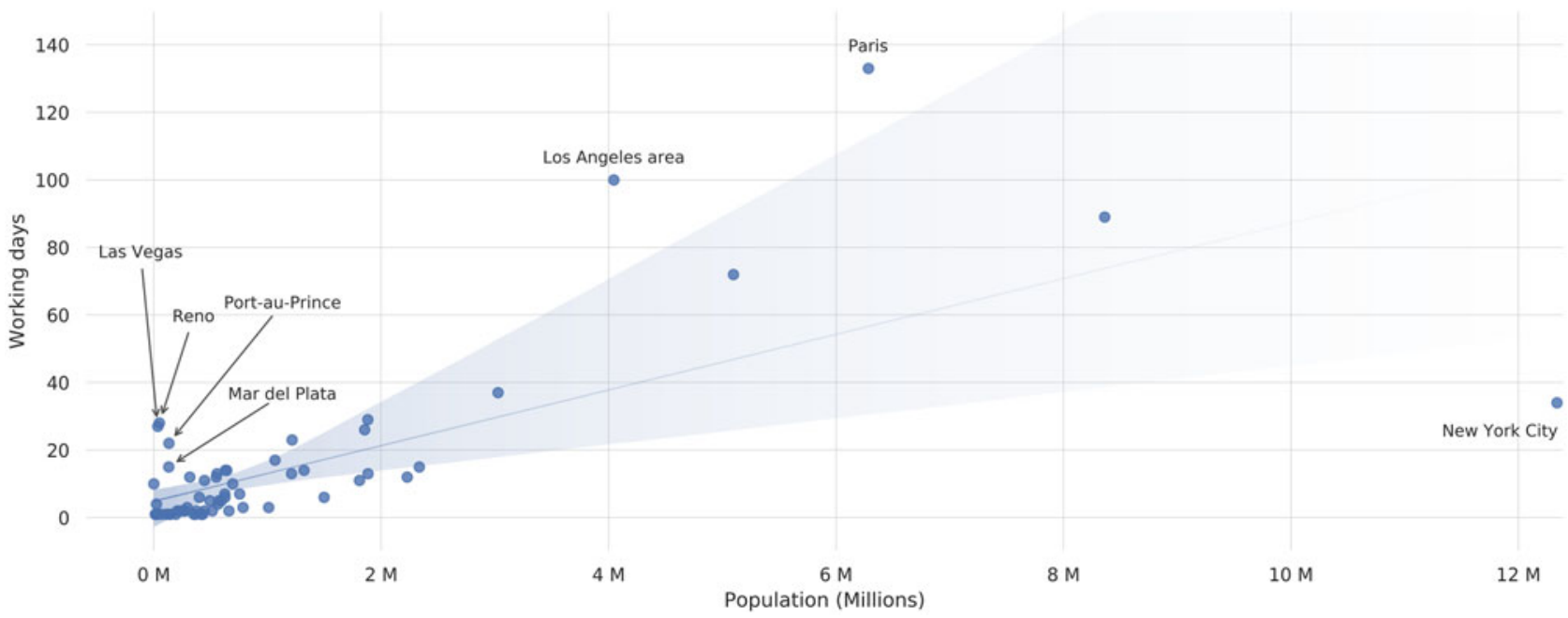

Figure 4. Relative city size to working days, 1950-3. This scatterplot plots city populations around 1950 against the time Dunham spent in a studio or theatre in those cities; 75 percent of the cities in which Dunham performed had populations below one million. We discuss specific outliers in the text.

Data: Harmony Bench and Kate Elswit. Visualization: Antonio Jiménez Mavillard. 
was likely "on her feet," so to speak, working in a studio or theatre across all stays in a city versus the population of that city. If we understand one of Dunham's goals to be financial stability, it stands to reason that she would have been better off with regular returns to cities where she had longer stays, which tended to be cities with populations over one million. Yet, this is not what we discover in the data. Instead, more than three-quarters of her engagements between 1950 and 1953 took place in cities with populations of fewer than 1.6 million, and almost all in cities with populations below 2.5 million. Even though Dunham's fan mail suggests that devoted audience members attended multiple performances when she was in town, smaller cities just could not supply the broad audience base to support longer stays. Whereas comparable artists would generally have a season of populous cities followed by a break, such as a summer holiday, Dunham had to keep moving on to the next city. Even over extended stays in larger cities, she often shifted between venues, upgrading or downgrading theatres, or appearing in nightclubs after an evening show. As we elaborate in the next section, the capacity to move between each of these venues indicates both Dunham's flexibility and the frictions that shaped and oriented her mobility.

For comparison, take choreographer José Limón, whose sponsorship by the US President's Special International Program for Cultural Presentations totaled $\$ 275,000$ between two international tours: one in 1954, during which his company toured South America, and another in 1957, when they toured Europe and the Middle East. ${ }^{33}$ In South America, the Limón Dance Company spent only one week in each of the large, east-coast cities of Rio de Janeiro, São Paulo, Montevideo, and Buenos Aires, with populations between 1.5 and 5.9 million. By contrast, Dunham spent ten months in South America in 1950, performing in fourteen cities of varying sizes in eight countries across the continent, and her 1954 tour lasted another five months along the east coast, where it conflicted with Limón's. In an unpublished retrospective, Dunham described the imbalance that she perceived in terms of both prestige and relative workload when they arrived in Montevideo to find it plastered with announcements for Limón's company: "We were a large company depending on impresarios for our survival. They were a small company (seven, I believe) financed by the State Department. No worries about transportation, crew, publicity, or whatever." ${ }^{34}$ She further noted that the American Ambassador made a speech to open Limón's show while refusing to appear at hers. $^{35}$

State Department backing had other benefits for sponsored artists. Remarking on Limón's reception by South American audiences, New York dance critic John Martin noted that he "did not alter his programs to remove the less popular works or to repeat the more popular ones." 36 By contrast, Dunham dancer Camille Yarborough tells an anecdote about changing repertory with short notice in Manila in 1957 at the behest of the president of the Philippines, who wanted to attend a second show. ${ }^{37}$ Even as some of Dunham's repertory challenged her audiences, performing works that did not receive an enthusiastic local response was not a luxury she could afford. In addition, State Department sponsorship disadvantaged independent artists more explicitly, by setting precedents for international theatres regarding how US artists would be subsidized during the 1950s. In a 1956 letter regarding negotiations for Dunham's later Japan engagement, a 
local manager informed Dunham that following "the intervention of A.N.T.A. ... no Japanese manager will ever be prepared to pay transportation costs." 38

Under these precarious conditions, all types of work were vital to maintaining solvency, some of which have not yet received the scholarly attention they deserve, but that have implications for evaluating Dunham's larger body of work. One result of plotting Dunham's whereabouts every single day is that the proportion of her work in nightclubs, casinos, and dinner cabarets-and the cities hosting these engagements-becomes visible. On the scatterplot (see Fig. 4), particular cities that are not well represented in Dunham scholarship appear among the outliers, including Los Angeles, Reno, Las Vegas, and Mar del Plata, Argentina, where they gesture to an important story about the tactics Dunham used to adapt and keep going. ${ }^{39}$ When Dunham returned to the United States in 1953, she performed with her company out West-visible in the cluster of sites in the upper left of Figure 1. During this period, Dunham visited the Los Angeles area eight times for a total of 132 nights across all stays. She spent almost that number of nights again in other parts of the western United States and Canada, including Las Vegas, Reno, Crystal Bay, San Francisco, and Vancouver. Adding these West Coast stays together, we come to a total of 256 nights over seventeen returns. The only other place Dunham spent this kind of time was Paris. Because all of the venues in which Dunham performed out West were nightclubs, tracking day by day not only illuminates the numerous cities that are not generally part of the Dunham narrative, but also draws our attention to the types of nonconcert venue that likewise have gone unrecognized. Whereas other choreographers, including Lester Horton and Alvin Ailey, are associated with occasional nightclub work in California during the 1940s and '50s, nightclubs occupy a substantial part of Dunham's engagements overall. Our analysis shows that roughly a quarter of Dunham's live performances during these four years took place outside of conventional concert venues, with a majority of these occurring during 1953. Across the subsequent "Everyday Itinerary Dataset, 1947-60," this proportion of concert venues to nightclubs and other spaces holds.

Although beyond the scope of this essay, nightclubs represent a locus of not only Dunham's audiences but also her art making, one that has not been fully examined. They call attention to the artificial divisions that are sometimes constructed between art and entertainment, and the risk of missing critical information when scholars disregard such experiences in assessing an artist's aesthetic or career. For example, as we have been building a separate dataset of Dunham's repertoire of more than two hundred dances, we notice that many pieces are misdated in the standard references, particularly if they premiered in nightclubs rather than conventional concert venues. Nightclubs were never Dunham's first choice, among other reasons because they were not as lucrative as concert engagements, but the concert versus nightclub distinction had implications for the structure of a show, the number of performers, and the pieces chosen as repertory within them. While concert venues most often involved one evening show per night, plus an additional matinee or two per week, and ran a couple hours long, nightclub venues tended to expect two to five shorter shows per night, often interspersed with other acts. Although the West Coast circuit is central in this time period to Dunham's US nightclub engagements, over a longer period we see Dunham 
performing in nightclubs, casinos, and hotels elsewhere in North America, including Mexico City and Miami, as well as internationally from Monte Carlo to Mar del Plata. Nightclubs thus become a key part in the narrative of ongoing transnational work that becomes visible by attending to Dunham's global method.

\section{Frictions and Flexibilities in Dunham's Transnational Mobility}

While our itinerary, calculations, and visualizations call attention to some of the relationships between Dunham's exceptional mobility and her pursuit of solvency, they can be misleading when taken out of context. They risk implying an easy to-and-fro among touring locations, without indicating the external forces that enabled or motivated Dunham to stay put or keep moving-forces that become vibrantly evident to us as we grapple with conflicting accounts of Dunham's whereabouts. In addition, stays that do materialize can have contradictory explanations. A lengthy stay might indicate that a show is going well and is profitable, or it could mean that Dunham is stuck-for example, due to the death or bankruptcy of impresarios-and has no other viable option than to remain where she is. A short stay might imply lack of audience interest, or it could demonstrate Dunham's uncanny ability to fill scheduling gaps with additional performances, thereby showing strong audience demand. Though the previous section focused on some of the insights that arise through accounting for Dunham's daily itinerary, this section looks at the small and large frictions that slowed or impeded Dunham's progress, and the ways Dunham flexibly adapted to ever-changing circumstanceswhich, in turn, generated more frictions. Within a framework of the everyday, mobility is neither inherently positive nor negative, but a negotiation that appears through overlapping configurations of factors that Dunham negotiated as a journeying Black woman, including transportation, finances, and well-being.

The very compressions of time and space that made international destinations available to Dunham for touring also increased the potential for what geographers call the "friction of distance" 40 -the space that must be traversed between two points, evaluated in terms of difficulty. Such difficulty may arise not only in relation to the modes of transportation available, but also through requirements for appropriate documents, financial liquidity, and the bodily ability to travel. Even if meeting these conditions, a traveler may still experience delays due to bureaucracy or racist encounters en route. In her ethnography of global environmental connections, industries, and activism, Anna Tsing theorizes such frictions that hold up travel, including "insufficient funds, late buses, security searches, and informal lines of segregation." ${ }^{41}$ For Tsing, coercion and frustration accompany freedom of movement as different "kinds of 'friction' [that] inflect motion." ${ }^{2}$ To understand such inflections better, we follow recent suggestions that the concept of friction can help scholars "to be sensitive to the heterogeneous and unequal encounters in the context of cross-border mobility." ${ }^{43}$ Mobility studies has begun to attend to the ways "(im) mobilities are important components of race as lived in everyday life." ${ }^{.4}$ In this section, we highlight some of the key frictions that emerge when constructing Dunham's itinerary, to arrive at the flexible ways she made do. Rather than highlighting exceptional moments, an everyday perspective calls attention to these negotiations with mobility as inextricable from an account of Dunham's global presence. 
First, there are the ways evolving transportation systems, and the duration and logistics of crossing borders, shaped Dunham's pathways. For example, while her dancers and even her personal secretary were frequently sent across the Atlantic on boats, Dunham tended to travel by airplane at a moment when flying was becoming increasingly popular as a middle-class activity. Yet, Dunham's aspirations often outpaced these technologies. Certain of her plans, such as a 1950 film shoot in Martinique, did not come to fruition because Pan Am had not yet built its planned airport there. ${ }^{45}$ On a separate occasion a performance was jeopardized when costumes did not arrive until 7:30 P.M. on opening night because the plane they were on developed engine trouble and was delayed for two days. ${ }^{46}$ Even the availability of transportation did not necessarily guarantee the capacity for international travel; in a 1955 letter that feels particularly timely now, Dunham explained that she performed a last-minute show in Mexico as a soloist, rather than with the initially planned twenty-seven performers, because she had an important show coming up in Chicago, and "With so many foreigners in the company I was worried about getting [the company] out [of Mexico and back in the United States] all in one piece."

As an African American traveling during the midcentury, often with a company of mostly Black performers, Dunham's archives call attention to how race shaped her travel pathways. Describing the rise of the Negro Travelers' Green Book in terms of the many valences of blatant and tacit "hostility" encountered while traveling in the United States during Jim Crow, Sullivan Sorin points out how "Blacks who succeeded economically traveled for business and for pleasure and in traveling made visible the injustice of segregation and the hypocrisy of white Americans touting equality and freedom." ${ }^{48}$ In one of Dunham's most blatant contemporaneous acknowledgments of US racial discrimination, she inquired about potential housing "problems" in 1955 when considering an engagement in Palm Springs, remarking, "[T]his was one of the reasons why I left the United States and I do not want to be bothered with it." ${ }^{\prime 9}$ Dunham sometimes had her white husband, John Pratt, book hotel rooms on their behalf, or she booked multiple rooms in a single city, presumably as insurance against the recurring reality of being refused accommodation in hotels where she had reservations. ${ }^{50}$ The capacity to remain in places such as Paris where company members felt a sense of "freedom" was likewise curtailed by the strain it placed on their finances. Dunham described the situation of remaining in Europe as one of "blackmail"; while they enjoyed "great success and good health," she felt unable to sustain the group financially, let alone turn a profit. ${ }^{51}$ Her statement recalls Brown's warning to recognize the contingency of freedom, rather than equating it with travel: "Black artists understood that freedom for them was a fragile thing, and that its instability crossed, or disregarded, national boundaries." 52

Further frictions arose in the tension between international touring and national finance structures. As a general rule, Dunham was paid (and in turn paid her performers and staff) in local currencies, which they then had to exchange for money to use either at the next touring destination or back in the United States, incurring massive fees-if they were able to exchange the currency at all. For one 1949 engagement, Dunham was paid in Swedish kronor, and, unable to deposit or exchange them, spent the next several months trying to use them. Dunham described the situation of "living abroad on a foreign exchange, buying black 
market dollars at a heavy penalty to send back to America, and then being taxed on the receipts figured at local bank rates" as unsustainable and unfair. ${ }^{53}$ It was also unreliable; for example, as much as $\$ 10,000$ was stolen from Dunham when she tried to get the money transferred from Argentina to New York. ${ }^{54}$ Perhaps for this reason, Dunham's letters contain recurrent discussions of jewelry, which function both as part of an economy of appearances, ${ }^{55}$ and as portable objects of value that can be liquidated into a local currency. ${ }^{56}$ In addition, Dunham's New York school, which might have offered the potential for economic mobility and, with it, greater geographic stability, instead produced more uncertainty. Dunham wrote to her assistant (and stage manager) Dale Wasserman in 1950 with concern about returning to New York City, because of arrest notices due to tax debts the school had accrued. ${ }^{57}$ In a heartbreaking moment in 1951, philanthropist Doris Duke offered a $\$ 75,000$ grant for the school, but the paperwork went astray while Dunham was abroad, and the money was allocated elsewhere. Dunham wrote in a letter that she thought "of how the course of all of our lives might have been changed and life and ambitions made so much more liveable except for the stupid failure on the part of a functionary." ${ }^{\prime 58}$ Dunham wished to pay off "enormous debts and striv[e] at some effort of future insurance," 59 but travel expenses, shipping costs, payroll, taxes and fees, fraud, and incompetence kept adding up, threatening Dunham's artistic survival and undermining her ability to get ahead. ${ }^{60}$

It is important to emphasize that, in spite of Dunham's ongoing financial struggles, she was rarely out of work. Rather, the absence of a consistent support structure forced her to piece together series of engagements in a variety of fields, primarily acting, in her words, as her "own impresario." This ad hoc approach often resulted in renegotiated contracts and disadvantageous terms, such as when she was asked to pay for transporting her troupe, which regularly numbered twenty-five people or more. ${ }^{61}$ Although Dunham's dancers experienced layoff periods-for example, due to changes in venue that determined cast sizes-days off were few and far between for Dunham herself. During 1950-3, our data show that Dunham was rehearsing or performing in a theatre or nightclub for at least 74 percent of the days $(1,078$ out of a total of 1,461$)$, sometimes appearing in multiple shows and even multiple venues in a single night. We have identified only 272 definitive nontheatre days, which often include travel days for the 134 individual trips contained within this period. When we begin to consider the types of activity Dunham undertook outside of a performance context-for example, researching local dance cultures for creative work, engaging in professional networking, writing essays and short stories, overseeing the mending of costumes or packing and shipping of props, or traveling from one performance venue to the next-the amount of "downtime" rapidly diminishes. Even when Dunham stayed for three months in Haiti convalescing after an appendectomy (which is why Port-au-Prince appears as another outlier in Figure 4), she used the time to plan a new show. ${ }^{62}$ We therefore believe the 74 percent figure to be a gross underestimate of the total amount of time Dunham was engaged in the work of artistically and financially sustaining her company. With the exception of an injury in Tokyo in late 1957 that kept Dunham from performing for almost a full year, she works consistently at this rate across our expanded 1947-60 itinerary dataset in progress. 
Faced with both the frictions and forced accelerations of keeping a touring group employed and maintaining the quality of the work, Dunham developed techniques of flexibility critical to her global method. However, just as mobility has multiple, unequal valances, flexibility is not a solution so much as a stop-gap measure, and can introduce further complications. Dance scholars have taken up flexibility as a framework through which to examine dance as labor. Anusha Kedhar literalizes the concept of flexibility in the bodily practices and material and affective labor of South Asian contemporary dance, by building on David Harvey's notion of "flexible accumulation" and Aiwa Ong's exploration of "flexible citizenship" amid contemporary neoliberal multiculturalism. Kedhar understands flexibility as a tactic of survival and agency that includes "a dancer's physical ability to stretch her limbs or bend her spine backward to meet the demands of a particular work or choreographer, her ability to negotiate immigration regulations and restrictions in order to move more easily across national borders, and her ability to pick up multiple movement vocabularies and deploy them strategically to increase her marketability and broaden her employment prospects." ${ }^{63}$ Kedhar emphasizes the flexibility of positioning required for the individual dance laborer, and employs the language of inflexibility to describe moments where "the transnational, racialized dancing body is immobilized either through injury or through immigration and citizenship restrictions." ${ }^{64}$ In contrast, we describe ongoing moments of friction that demanded flexible responses from Dunham not only as an individual dancer, but also as a transnational choreographic entrepreneur.

The geographic and temporal contortions of Dunham's touring schedule were interconnected with the shifting organization of her troupe, which adapted to the multiple forms of work that the company took on in both theatres and nightclubs. ${ }^{65}$ Dance numbers regularly moved back and forth between stripped-down (club) and full-sized (concert) versions, impacting how many performers Dunham employed. According to a repertory list that Dunham assembled in the late 1950s, as many as half of her theatrical pieces had nightclub versions, in addition to which there were distinct nightclub pieces. ${ }^{66}$ Dunham's nightclub engagements appear three ways in her itinerary: as a late-night engagement after a concert performance, as a placeholder between two concert engagements, or as a stop-gap until the next concert tour was finalized. Dunham preferred the concert work, which paid better and employed significantly more dancers, but she relied on the nightclubs, which were her means of making do "for as long as I can, until a full show materializes." ${ }^{\text {"67 }}$ Relying on nightclub work to bridge the gap, she reorganized her troupe to accommodate these smaller venues. For example, in 1952, she closed her concert show in London and sent half of the company on layoff, while she and the others remained to work in a nightclub for the three weeks before their engagement in Belfast "in order to cover the expenses," as she wrote to her mother. ${ }^{68}$ Similarly, filling time before a tour to South America and awaiting a contract with Hurok, Dunham wrote that she would "have to be separating the Company in order to play the clubs," leaving some of her dancers without work for the summer. ${ }^{69}$

Dunham's ability to rearrange her repertory and company size flexibly was, of course, somewhat of a catch-22. At the same time as the nightclub work was essential to maintaining short-term solvency, her success in the popular domain at times 
undermined her visibility as a "serious" artist. When the US State Department consulted the Advisory Committee on the Arts regarding sending Dunham abroad for a lecture engagement in 1964 that never materialized, many panelists were supportive, but one complained that Dunham "just loves money," and another opined that her recent productions had been "of the nightclub type."70 Likewise, her variable company structure allowed her to lay off and pick up performers on an as-needed basis with perpetual short-term contracts, but it also allowed performers to depart with little notice, sometimes leaving Dunham scrambling to fill positions. These sites of friction reveal the contingency of Dunham's success and the constant process of negotiation that enabled her to keep going. However, responding flexibly in the short term worked at cross-purposes with long-term financial stability and took a physical and emotional toll on everyone.

\section{On Well-being}

Dunham, who was in her early forties at this time, considered her ability to keep going thanks to her "indestructible physique" as a privileged kind of endurance amid the constant push that she sometimes described as a "rat race."71 Quantifying Dunham's labor with such statistics as the percentage of days in theatres and median stay length hints at the kind of wear and tear that such an extensive touring schedule might place on dancers' fallible bodies, which Dunham's archival materials elaborate. For example, after a particularly difficult stretch, Dunham remarked that she had gone through "a terrible period which I hope will never be repeated and it has taken all kinds of hard work under every physical strain to try to see the way clear," and that she was trusting her health to hold out for two years so she "can work without stopping" in order to repay loans. ${ }^{72}$ Unfortunately, but perhaps predictably, her health did not hold out under this sustained pressure. Though dance scholarship generally accounts for embodiment in analyzing choreographic works and the dancers who perform them, working at the scale of the everyday amplifies the link between mobility and well-being in Dunham's global method. Replacing the language of endless flow with concrete examples of "how globalization has literally stretched transnational dancing bodies to breaking point," Kedhar points out that injuries make the fragility of the body visible. $^{73}$ In this final section, we turn our attention to how Dunham wrote about her own bodily experience in a manner that drew together her performance workload, financial precarity, physical drain, and geographic reach.

One such example appears in a letter Dunham wrote in 1953 from Reno to her friend Bernard Berenson. In it, Dunham moves between accounts of physiological tiredness, from "years and years with so little rest" to recent sleeplessness and a shift in her body rhythms due to the nearby testing of an atomic bomb, to psychological tiredness. While her account of psychological fatigue begins in relatively abstract terms of feeling at a dead end, it becomes increasingly particularized in a detailed critique of working "within touching distance" of the white hustlers, gamblers, and prostitutes who could afford to attend the casino nightclubs. In particular, she contrasts her own physical strain as a performer with the cavalier attitudes of the audience: "while one works with perspiration dripping over one's false eyelashes and a knee with a floating cartilage threatening betrayal at any minute and muscle joint 
and heart weariness struggling to take control, this great sodden beast eats steak, drips spaghetti, guzzles bourbon, talks, laughs, and once in a while gets up to go to the water closet." ${ }^{\prime 74}$ In this evocative passage, Dunham viscerally represents the sweat of a performance as she labors to produce pleasure for an audience consuming her image in the same grotesque manner that they eat and drink. She captures her demoralization through the physical reality of performing with weary muscles, joints, and heart-a fatigue accompanied by the very real threat that her body would give way to injury. Rather than writing off the performances, however, she subsequently turns to a discussion of subverting audience expectations for Black performers in such venues and makes a case for her work's important intervention.

Well-being was not a category of experience we were looking for as researchers, but it arose as a result of tracing Dunham's global method through an everyday perspective. With the spectrum of well-being, we refer both to the days when Dunham reported continuing to dance either with acute pain or with the help of injections such as morphine or cortisone, ${ }^{75}$ and to moments when she simply remarked that she felt good. Dunham frequently described mundane and overlapping complaints, including problems with her knee, back, foot, and "joints" more broadly. In a host of descriptive passages she connected weather and geography, such as the presence or absence of sun, with its impact on her physical state. Across more than one hundred examples of such moments in the 1950-3 archives, only two events produce an enforced rest of days or weeks. In the first, showing how physical issues compounded financial stresses, Dunham wrote in 1951 that they had planned a heavy tour schedule to make up for recent financial losses, but she was then stricken with an attack of appendicitis that completely prevented her from performing. ${ }^{76}$ In the second, Dunham suffered a miscarriage in London in 1952 that coincided with the death of King George VI, allowing her to take a week off from performing, "which we could fortunately cloak in national mourning."77 Beyond such acute events, the majority of her physical complaints were like her knee threatening to give way in the passage above-an everyday and ongoing kind of negotiation with well-being that had significant impact on her work since, as she put it: "The aesthetic part as far as I am concerned is naturally superseded by the purely practical one of being able to go on from day to day whether it be in bistro, theater, or classroom.." ${ }^{78}$

The toll that touring took on Dunham might be understood in relation to depletion, an environmental metaphor used to describe the social costs of hidden or uncompensated labor within everyday political economies. Scholars of depletion point to imbalances between individual and communal effort-what they call "outflows" - and "the inflows that sustain ... health and well-being." ${ }^{.79}$ While it is easy to see Dunham's onstage performances as work, depletion expands that category, by positioning the fatigue that she so often mentions in relation to her overall workload, from administrating to networking to travel. The ongoing care and maintenance for a dancing body was likewise another part of her ongoing labor; in general, Dunham performed through chronic injuries, with physical stresses compounded by the question of where and when the need to take time off might disrupt her forward momentum. Positioning depletion against Dunham's global method also recontextualizes her transnational labor within discussions on "weathering," specifically the disproportionate health toll that marginalization takes on Black subjects, across classes. ${ }^{80}$ 


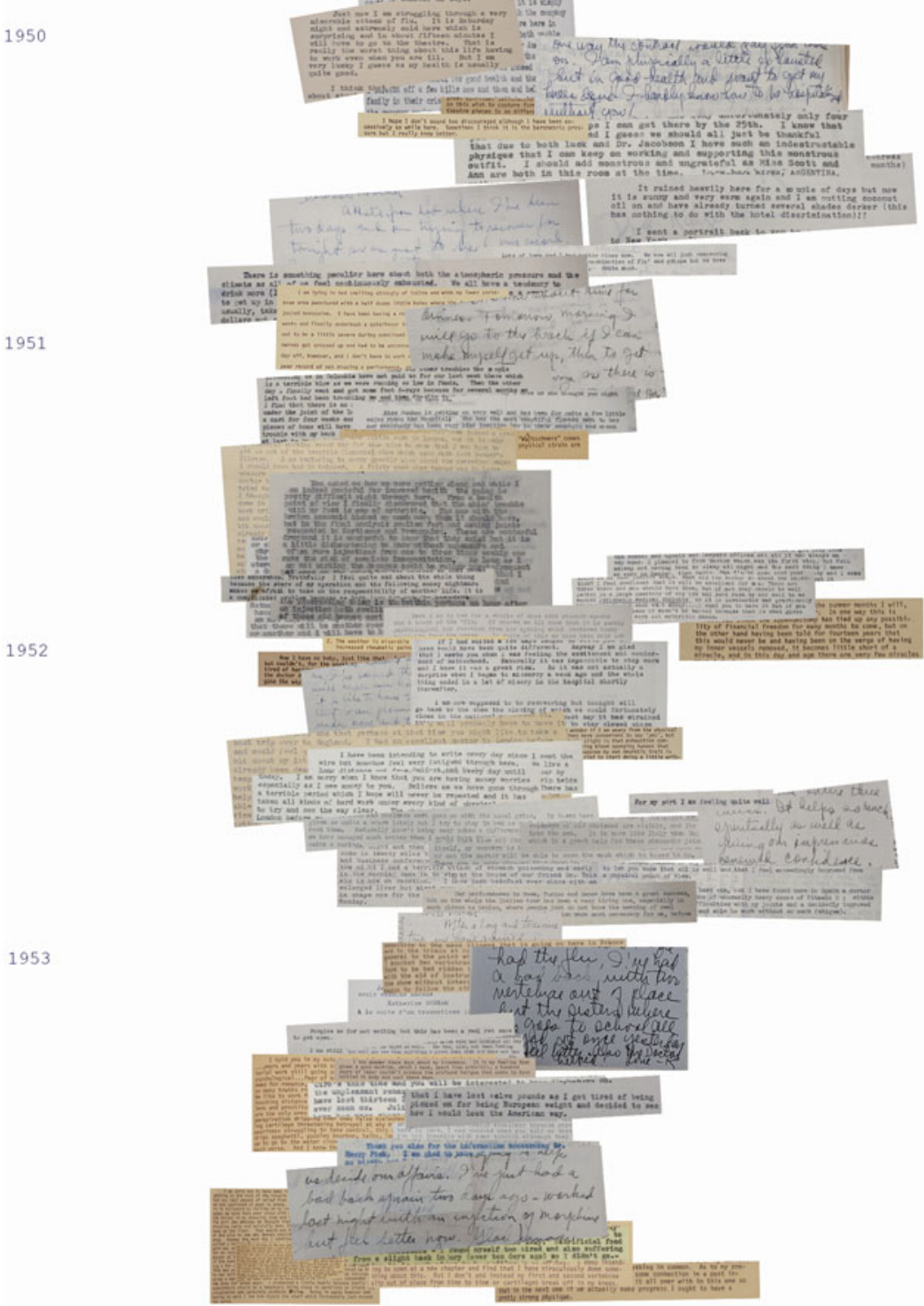

Figure 5. Well-being timeline collage, 1950-3. Clippings from Dunham's correspondence that involve thick descriptions of physical states, ordered sequentially on a vertical timeline, and horizontally by sentiment. These call attention the compounding impact of wear and tear over time. Curation and visualization: Harmony Bench and Kate Elswit.

In Figure 5, we layer photographs of passages from Dunham's letters as she reports on her own well-being during these four years on the road. Dunham is generally forthright in her letters, cataloging medical diagnoses and personal 
observations, together with her coping mechanisms for working through injury-a common reality for many dancers. At times she expresses herself in a manner that is resigned; at others, frustrated or even wryly humorous. Because Dunham used "feeling" as a relatively standard turn of phrase, we draw out examples of well-being from passages in which her thoughts and feelings are interwoven with embodied experience, as in the example from the 1953 letter from Reno. Using archival materials themselves rather than transcription, together with the overlapping layers, offers some degree of privacy. The vertical axis serves as a timeline of letters written over the four years, while the horizontal axis is oriented by degrees of what we interpret as comparatively positive or negative sentiment expressed toward the states that these passages describe. In the same way that each datapoint tells a story, we found that the act of positioning lends itself to further consideration for the well-being experience that each quotation represents; we noticed how some descriptions express good feeling in relation to past or subsequent setbacks, and vice versa. Bringing together these individual days, the collage foregrounds the ongoing low- to midlevel physical drains, few of which stopped Dunham's trajectory outright, that hung over it nonetheless. For example, we find it conspicuous that the accumulation of clips on the left side of the image coincides with that fast-paced movement through "other cities" in late 1952 through mid-1953 in Figure 2. ${ }^{81}$

The physical effects of Dunham's transnational mobility are an important part of her lived geographies, and the individual days and the cumulative daily impacts of being on the road scale like other aspects of Dunham's everyday. However, the ethical questions that arise for us around how to maintain Dunham's physicality and subjectivity at the center of, say, an itinerary, become even more acute when engaging with an everyday history of well-being. These questions press on the conversation with which we began this essay, regarding the limits of conveying embodied experience in conversation with data. In Geographies of the Holocaust, Gigliotti, Masurovsky, and Steiner ask: "How can one map experience rigorously, or convey the power of emotion in the contexts of motion and stasis? Is it possible to be both rigorous and evocative? How can one preserve the richness and nuance of an individual's experience while connecting that person meaningfully to the places where events occurred? And how can one draw general insights from intensely personal accounts?" 82 To these questions we add: How does embodied experience inform a broader study of movement on the move in terms of performance and travel? Can an everyday perspective acknowledge the compounding effects of Dunham's global method by collecting together her thick descriptions of individual physical states, or will such an endeavor always risk being too physical and too personal? Perhaps the answer lies in Dunham's evocative 1953 passage, which articulates so clearly how embodiment is not just about materiality but that physicality also serves as both an individual and collective site for processing, imagining, and feeling.

\section{Conclusion}

Transforming archival materials into usable datasets by manually cataloging Dunham's exceptional transnational mobility over the four years 1950-3, we draw attention to the everyday as a granular analytic that can shed new light on lived experience. While building rough outlines of such itineraries is the same 
work required to construct a traditional historical narrative, the scope of the itineraries and the uses to which we put these data are markedly different. Rather than offer an overview of Dunham and her career that highlights standout moments or specific choreographic works, our analysis takes place at the scale of the quotidian. With this, we join other theatre and dance scholars who are shifting our collective attention away from the spectacularly successful to the average majority, and from the high art-low class dichotomy toward the middlebrow. ${ }^{83}$ Dunham's celebrity and indisputable importance as an African American artist complicate framing her work in these terms; but as we show throughout this essay, the emphasis on Dunham's singular achievements has obscured her daily navigations and ongoing efforts to gather the support to keep her company going. Instead, we wish to trace the specific ways that, as McKittrick argues, "black women's geographies are lived, possible, and imaginable." 84 Dunham's archives sit at the interstices of "space, place, and blackness" that McKittrick describes as "uneven sites of physical and experiential 'difference." 85 We address such differences in terms of the relationship between mobility and solvency that inform Dunham's global method.

From the perspective of the everyday, transnational circulation demonstrates an international audience for Dunham's work, but intensive travel is not necessarily purely positive. One of the most successful choreographers of the twentieth century, Dunham traveled far more than her subsidized contemporaries and experienced ongoing precarity. How does this complicate barometers for artistic success, in particular for Dunham as an African American female artist? In this essay, we argue that nightclubs are one place to begin to answer this question. However, as we expand the itinerary and further account for the hundreds of dancers, drummers, and singers in Dunham's employ and the hundreds of dances in her repertory, we are coming to see similar registers of instability as a constant, from the flexible nature of her company structure, to the mutability of her dances as she repurposed material for different works and contexts. This very adaptability makes evident the practices of making do, practices that helped to propel Dunham's work into the world, as additional mobilities that need to be accounted for within her diasporic practice.

In the broader Dunham's Data project, we seek to understand the questions and problems that make the analysis and visualization of data meaningful for dancehistorical analysis. Situating this project in conversation with the broad fields of digital humanities, geo- and spatial humanities, and cultural analytics, we continue to investigate the unique analytical methods that dance not only requires but also offers to interdisciplinary study. While bodily experience poses a challenge to digital analysis and representation, attending to the bodies in and through the data can help us to evidence and elaborate embodied experiences both on and off the stage. Constructing Dunham's daily itinerary was originally meant to support our analyses of the ephemeral corporeal practices of dance's transnational circulation and transmission. However, working with this dataset has offered enormous insight into the material circumstances of circulation itself.

\section{Notes}

1 Correspondence, 1 January 1950, Box 14, Folder 6, Katherine Dunham Papers, Southern Illinois University, Carbondale, IL, USA (hereinafter, SIU). 
2 VèVè Clark, "Performing the Memory of Difference in Afro-Caribbean Dance: Katherine Dunham's Choreography, 1938-87," in History and Memory in African-American Culture, ed. Geneviève Fabre and Robert O’Meally (New York: Oxford University Press, 1994), 188-204.

3 For foundational scholarship on Katherine Dunham, see Clark, "Performing the Memory of Difference"; VèVè A. Clark and Sarah E. Johnson, eds., Kaiso! Writings by and about Katherine Dunham (Madison: University of Wisconsin Press, 2005); Joanna Dee Das, Katherine Dunham: Dance and the African Diaspora (New York: Oxford University Press, 2017); Susan Manning, Modern Dance, Negro Dance: Race in Motion (Minneapolis: University of Minnesota Press, 2004); Halifu Osumare, "Dancing the Black Atlantic: Katherine Dunham's Research-to-Performance Method," AmeriQuests 7.2 (2010), doi:10.15695/amqst.v7i2.165.

4 Harmony Bench and Kate Elswit, "Mapping Movement on the Move: Dance Touring and Digital Methods," Theatre Journal 68.4 (2016): 575-96, doi:10.1353/tj.2016.0107.

5 Catherine D'Ignazio and Lauren F. Klein, Data Feminism (Cambridge, MA: MIT Press, 2020); Elizabeth Losh and Jacqueline Wernimont, ed., Bodies of Information: Intersectional Feminism and Digital Humanities (Minneapolis: University of Minnesota Press, 2018).

6 Marisa Parham, "Digital Archives, Datum Storytelling, \& the Future of Memory," at the 37-minute mark of Library of Congress, "Developing Communities of Practice," 27 September 2016, www.youtube.com/ watch? $\mathrm{v}=\mathrm{bxWv0pv1140} \mathrm{(accessed} 10$ September 2018); see also the ongoing project "Living with Personal Data," led by Deborah Lupton, https://livingwithpersonal.data.blog/ (accessed 3 August 2019).

7 For example, Ruha Benjamin, Race after Technology: Abolitionist Tools for the New Jim Code (Cambridge: Polity Press, 2019); Caitlin Rosenthal, Accounting for Slavery: Masters and Management (Cambridge, MA: Harvard University Press, 2018).

8 Jessica Marie Johnson, "Markup Bodies: Black [Life] Studies and Slavery [Death] Studies at the Digital Crossroads," Social Text 36.4 (2018): 57-79, at 58, doi:10.1215/01642472-7145658.

9 Ibid., 71.

10 Johanna Drucker, "Humanities Approaches to Graphical Display," DHQ 5.1 (2011) www.digitalhumanities. org/dhq/vol/5/1/000091/000091.html (accessed 15 November 2018); Miriam Posner, "What's Next: The Radical, Unrealized Potential of Digital Humanities," Debates in the Digital Humanities 2016, ed. Matthew K. Gold and Lauren F. Klein (Minneapolis: University of Minnesota Press, 2016), https://dhdebates.gc.cuny. edu/read/untitled/section/a22aca14-0eb0-4cc6-a622-6fee9428a357\#ch03 (accessed 15 November 2018).

11 We extend this argument in our forthcoming essay "The Body Is Not (Only) a Metaphor: Rethinking Embodiment in DH," in Debates in the Digital Humanities 2022, ed. Matthew K. Gold and Lauren F. Klein (Minneapolis: University of Minnesota Press).

12 We write about scale more broadly in relation to digital methods for performance history in Bench and Elswit, "Mapping Movement on the Move."

13 Kamari Maxine Clarke, Mapping Yorùbá Networks: Power and Agency in the Making of Transnational Communities (Durham, NC: Duke University Press, 2004), xxii.

14 Our understanding of the everyday is informed by the postwar everyday life theory associated with Henri Lefebvre and later Michel de Certeau, as well as the feminist argument in the 1990s for the political potential of particularizing everyday experiences. More recent theorizations of the everyday that have a bearing on our analysis of Dunham include Lauren Berlant's exploration of the "crisis ordinary" and Elizabeth Povinelli's discussion of endurance and exhaustion within late liberalism. See Lauren Berlant, Cruel Optimism (Durham, NC: Duke University Press, 2011), 9-10; Elizabeth A. Povinelli, Economies of Abandonment: Social Belonging and Endurance in Late Liberalism (Durham, NC: Duke University Press, 2011).

15 Katherine McKittrick, Demonic Grounds: Black Women and the Cartographies of Struggle (Minneapolis: University of Minnesota Press, 2006), 21.

16 Ibid., xxxi.

17 Jayna Brown, Babylon Girls: Black Women Performers and the Shaping of the Modern (Durham, NC: Duke University Press, 2008), 10.

18 Since first writing this essay, we have extended the Everyday Itinerary Dataset to cover 1947-60, and occasionally reference that material here as well. The 1950-3 dataset is available at Harmony Bench and Kate Elswit, "Everyday Itinerary Dataset, 1950-53," Dunham's Data: Katherine Dunham and Digital Methods for Dance Historical Inquiry, National Archive of Data on Arts and Culture (distributor), 1 August 2020. http://doi.org/10.3886/ICPSR37698.v1. We will release updates to this dataset with further years. 
19 For example, if we were able to establish that Dunham flew from city $A$ to city $B$ in the first half of a certain week, then we could discover from flight route maps that the only airline to fly that route in spring of 1951 did so on Tuesdays and Thursdays, and therefore the trip had to have taken place on the Tuesday. 20 An example is available at Harmony Bench and Kate Elswit, "Datasets Are Research," Dunham's Data Research Blog, 5 September 2019, www.dunhamsdata.org/blog/datasets-are-research.

21 For example: correspondence, 19 January 1950, Box 14, Folder 7, SIU.

22 For example: Stephanie Jordan, "The Demons in a Database: Interrogating 'Stravinsky the Global Dancer," Dance Research 22.1 (2004): 57-83; Jane Pritchard, "Serge Diaghilev's Ballets Russes-An Itinerary. Part 1: 1909-1921,” Dance Research 27.1 (2009): 108-98, doi:10.3366/E0264287509000279; Christena L. Schlundt, The Professional Appearances of Ruth St. Denis \& Ted Shawn; A Chronology and An Index of Dances, 1906-1932 (New York: New York Public Library, 1962).

23 Among other projects that employ digital methods to attend to both macro and micro scales of inquiry, the Geographies of the Holocaust project shifts between scales in order to expand analytic perspectives on an event that is both massive and profoundly personal. Paul B. Jaskot and Tim Cole, "Afterword," in Geographies of the Holocaust, ed. Anne Kelly Knowles, Tim Cole, and Alberto Giordano (Bloomington: Indiana University Press, 2014), 227-32, at 229. In the field of performance, Derek Miller contends that "the vast majority of theatre scholarship is a history of prodigious exceptions," in an art form dominated by unpopular shows and commercial failures, and turns to the quantitative analysis of "average Broadway." Derek Miller, "Average Broadway," Theatre Journal 68.4 (2016): 529-53, at 546, doi:10.1353/tj.2016.0105. 24 This approach is commonly used to analyze patterns of migration and travel, such as those found at movebank.org, and http://meipokwan.org/Gallery/STPaths.htm (both accessed 15 November 2018). Time geography also appears in the digital theatre history project IbsenStage to visualize connections, continuity, and change among productions of A Doll's House. See Jonathan Bollen and Julie Holledge, "Hidden Dramas: Cartographic Revelations in the World of Theatre Studies," Cartographic Journal 48.4 (2011): 226-36, doi:10.1179/1743277411Y.0000000026.

25 As we have expanded the Everyday Itinerary Dataset to encompass 1947-60, Antonio Jiménez Mavillard has needed to build an interactive three-dimensional globe in order to account for travel across both the Atlantic and Pacific Oceans.

26 See Clare Croft, Dancers as Diplomats: American Choreography in Cultural Exchange (Oxford and New York: Oxford University Press, 2015); Naima Prevots, Dance for Export: Cultural Diplomacy and the Cold War (Middletown, CT: Wesleyan University Press, 2001).

27 See "Mapping Touring," Movement on the Move, http://movementonthemove.osu.edu/project-mappingtouring, accessed 14 December 2018.

28 For more detail on this calculation, see Antonio Jiménez Mavillard, "First Things First: Days and Nights," Dunham's Data Research Blog, 1 August 2019, www.dunhamsdata.org/blog/first-thing-firstdays-and-nights.

29 In addition to cities where Dunham spent one or more nights, a city is also counted as a stay if an overnight trip left from there. There are also a substantial number of uncounted transit cities in which she stayed some number of hours, but not overnight.

30 Correspondence, 4 March 1950, Box 39, Folder 1, SIU.

31 Contractual agreement, 28 January 1950, Box 14, Folder 7, SIU.

32 "Atlanta Dancer Home for Brief Rest between Tours Atlanta Daily World (1932-2003)," Atlanta Daily World, 29 April 1951.

33 Philip Warden, “U.S. Culture Goes Dancing 'Round the World: For \$275,000," Chicago Daily Tribune, 8 May 1958, B4.

34 Katherine Dunham, "Love Letters from I Tatti," unpublished manuscript, Robert Park Mills Papers, Folder 14, Boxes 2-3, 218, Harry Ransom Humanities Research Center, University of Texas at Austin.

35 Although Dunham attributed her lack of State Department funding to the repercussions of her controversial Southland performance in Chile in late 1950, her archives evidence financial instability both earlier and later than this common narrative would suggest. A wider-angle view is therefore necessary to understand the economic entanglements of Dunham's global method. See Constance Valis Hill, "Katherine Dunham's Southland: Protest in the Face of Repression," in Dancing Many Drums: Excavations in African American Dance, ed. Thomas F. DeFrantz (Madison: University of Wisconsin Press, 2002), 289-316, at 310. 
36 John Martin, "The Dance: Diplomacy-Limon Makes Conquest in South America," New York Times, 23 January 1955, X11.

37 Conversation between Camille Yarborough and Takiyah Nur Amin, October 2019.

38 Correspondence, 8 September [1956], Box 21, Folder 3, SIU.

39 In terms of other outliers, the disproportionately low positioning of New York City further bolsters the need to look elsewhere by the 1950s. Dunham also stays much longer than expected in other cities, including in Port-au-Prince, where she had spent time as an anthropologist and eventually purchased an estate. 40 David Harvey, "Space as a Keyword," in David Harvey: A Critical Reader, ed. Noel Castree and Derek Gregory (Malden, MA: Blackwell, 2006), 275.

41 Anna Lowenhaupt Tsing, Friction: An Ethnography of Global Connection (Princeton, NJ: Princeton University Press, 2005), 5.

42 Ibid., 6.

43 Joris Schapendonk et al., "Re-Routing Migration Geographies: Migrants, Trajectories and Mobility Regimes," Geoforum (accepted June 2018), doi:10.1016/j.geoforum.2018.06.007.

44 Tim Cresswell, "Black Moves: Moments in the History of African-American Masculine Mobilities," Transfers 6.1 (2016): 12-25, at 22, doi:10.3167/TRANS.2016.060103; see also Judith A. Nicholson and Mimi Sheller, "Race and the Politics of Mobility-Introduction," Transfers 6.1 (2016): 4-11, doi:10.3167/ TRANS.2016.060102.

45 Telegrams, 7 January and 13 January 1950, Box 14, Folder 6, SIU.

46 Correspondence, 18 June 1950, Box 39, Folder 2, SIU.

47 Correspondence, 5 October 1955, Box 19, Folder 7, SIU.

48 Gretchen Sullivan Sorin, "Keep Going': African Americans on the Road in the Era of Jim Crow" (Ph.D. diss., Dept. History, State University of New York at Albany, 2011), 241. Although the moments of decreased friction are few and far between, in 1956, while the NAACP was urging boycotts of yellow cabs, the company received an invitation from a private car company for free rides the whole time they stayed in San Francisco.

49 It is worth noting that another letter around the same time attributes this to the union pay scales required there. Correspondence, 14 January 1955, Box 17, Folder 7, SIU, and 14 August 1955, Box 19, Folder 3, SIU.

50 Such events were not limited to the United States, as evidenced by a well-publicized July 1950 incident in which Dunham was refused accommodation at a hotel in São Paulo, Brazil. See "Brazil Enacts Law against Race Bias," Atlanta Daily World, 8 July 1951, 1.

51 Correspondence, 3 January 1950, Box 14, Folder 6, SIU, and 5 February 1950, Box 14, Folder 8, SIU.

52 Brown, 242.

53 Correspondence, 18 January 1950, Box 14, Folder 6, SIU.

54 Correspondence, 25 March 1951, Box 39, Folder 4, SIU.

55 Tsing, Friction, 57.

56 This is most explicitly articulated in correspondence, 18 October 1954, Box 17, Folder 4, SIU, and also borne out in interviews with dancers. Thanks to Jonathan Bollen for encouraging us to consider jewelry as a type of international currency.

57 Correspondence, 26 February 1950, Box 14, Folder 8, SIU. See also: correspondence, 25 December 1953, Box 16, Folder 9, SIU.

58 Correspondence, 21 November 1951, Box 39, Folder 4, SIU.

59 Correspondence, 18 October 1951, Box 15, Folder 9, SIU.

60 Amid this, Dunham's project of keeping up appearances was critical in enabling her to cultivate and leverage a vast network to support the dance company. Stuck in San Francisco in 1955, for example, Dunham made several appeals to benefactors for loans to get her dancers and musicians to Chicago, where they would begin a tour late in October, promising repayment immediately after performances began. Correspondence, 5 October 1955, Box 19, Folder 7, SIU.

61 Correspondence, 5 October 1955, Box 19, Folder 7, SIU. While she did contract with local managers and impresarios, and was also supported by Dale Wasserman, who was often the intermediary in such negotiations, her archives do not show the kind of singular overarching management structure or systematic planning that is comparable to other Hurok-managed artists, for example.

62 Correspondence, undated (ca. 1951), Box 15, Folder 9, SIU. 
63 Anusha Kedhar, "Flexibility and Its Bodily Limits: Transnational South Asian Dancers in an Age of Neoliberalism," Dance Research Journal 46.1 (April 2014): 23-40, at 24, doi:10.1017/S0149767714000163; on dance and flexibility, see also Yatin Lin, "Choreographing a Flexible Taiwan: Cloud Gate Dance Theatre and Taiwan's Changing Identity," in The Routledge Dance Studies Reader, 2d ed., ed. Alexandra Carter and Janet O'Shea (New York: Routledge, 2010), 250-60.

64 Kedhar, 26.

65 See Das, 206-7.

66 "Timings of Repertoire," 6 October 1959, Box 25, Folder 8, SIU.

67 Correspondence, 14 June 1953, Box 39, Folder 5, SIU.

68 Correspondence, 2 May 1952, Box 39, Folder 4, SIU.

69 Correspondence, 21 February 1953, Box 39, Folder 5, SIU.

70 Katherine Dunham, FBI File, 100-334795, 12 February 1964.

71 Correspondence, 14 May 1950, Box 39, Folder 2, SIU; and 21 May 1952, Box 39, Folder 4, SIU.

72 Correspondence, 2 May 1952, Box 39, Folder 4, SIU.

73 Kedhar, 35.

74 Dunham, "Love Letters from I Tatti," 17 June 1953, 175.

75 Correspondence, 1 October 1953, Box 39, Folder 5, SIU, and undated ca. 1951, Box 15, Folder 9, SIU.

76 Correspondence, 25 March 1951, Box 39, Folder 4, SIU.

77 Correspondence, 13 February 1952, Box 16, Folder 1, SIU.

78 Correspondence, undated ca. 1951, Box 15, Folder 9, SIU.

79 Shirin M. Rai, Catherine Hoskyns, and Dania Thomas, "Depletion: The Cost of Social Reproduction," International Feminist Journal of Politics 16.1 (2014): 86-105, at 86, doi:10.1080/14616742.2013.789641. 80 Thanks to Takiyah Nur Amin for this connection. See A. T. Geronimus, "The Weathering Hypothesis and the Health of African-American Women and Infants: Evidence and Speculations," Ethnicity \& Disease 2.3 (1992): 207-21.

81 In exploring how we might keep this material as part of Dunham's global method, we drew inspiration from a variety of scholars working to represent personal data, in particular the Geographies of the Holocaust project's use of "expressive visualizations" as a flexible means to extract and represent experiences from the archive that support historical understanding, as well as Stefanie Posavec and Giorgia Lupi's Dear Data project (2015), which favors an analog approach to representing the individual and communal experiences that the data signify.

82 Simone Gigliotti, Marc J. Masurovsky, and Erik B. Steiner, "From the Camp to the Road: Evacuations from Auschwitz, January 1945," Geographies of the Holocaust, 192-225, at 207.

83 Miller, "Average Broadway"; Judith Hamera, "Rehearsal Problems: Gus Giordano's The Rehearsal and the Serious Business of Middlebrow Dance," Theatre Journal 71.2 (2019): 171-89; Brian Herrera, "The Many Middling Failures of Virginia Calhoun," Theatre Topics 28.1 (2018): 75-81.

84 McKittrick, Demonic Grounds, xii.

85 Ibid., 3.

Harmony Bench (www.harmonybench.com) is Associate Professor in the Department of Dance at The Ohio State University. Her research addresses dance in the contexts of digital and screen media. She is the author of Perpetual Motion: Dance, Digital Cultures, and the Common (University of Minnesota Press, 2020). She has also contributed to The Bloomsbury Companion to Dance Studies, Routledge Dance Studies Reader (3d ed.), The Oxford Handbook of Dance and the Popular Screen, Choreographies of 21st Century War, and Dance on Its Own Terms, among others. Harmony currently collaborates with Kate Elswit on the AHRC-funded digital humanities and dance history project Dunham's Data: Katherine Dunham and Digital Methods for Dance Historical Inquiry. https://unhamsdata.org/.

Kate Elswit (www.kateelswit.org) is the author of Watching Weimar Dance (2014), winner of the Oscar G. Brockett Book Prize for Dance Research and honorable mention for the Callaway Prize, and of Theatre \& Dance (2018). Her current research includes a monograph on the intersections of breath, performance, and measurement from the Victorian era to the present, as well as the digital humanities project Dunham's Data: Katherine Dunham and Digital Methods for Dance Historical Inquiry, in collaboration with Harmony Bench, which is funded by the AHRC (https://dunhamsdata.org/). She received her 
Ph.D. from the University of Cambridge, and is now Reader in Theatre and Performance at the Royal Central School of Speech and Drama, University of London.

Cite this article: Harmony Bench and Kate Elswit, "Katherine Dunham's Global Method and the Embodied Politics of Dance's Everyday," Theatre Survey 61.3 (2020): 305-330. https://doi.org/10.1017/ S0040557420000253. 